\title{
A importância da América Latina para a recentralização asiática no sistema-mundo
}

\author{
The importance of Latin America for the Asian \\ recentralization in the world-system
}

Bernardo Salgado Rodrigues ${ }^{\mathrm{a}}$ e Carlos Eduardo da Rosa Martins ${ }^{\mathrm{b}}$

\begin{abstract}
Resumo O presente artigo busca delinear e debater a hipótese da importância latinoamericana para a recentralização asiática - ou reorientalização - no sistema-mundo. A partir da perspectiva da longa duração, busca-se apresentar a dualidade de um sistemamundo milenar centrado na Ásia e a ascensão de um sistema-mundo europeu no século XVI. Assim, a periferização asiática diante do apogeu do sistema-mundo capitalista europeu a partir da Revolução Industrial começa a ser revertida no final do século $\mathrm{XX}$, cujo eixo gravitacional é recentralizado para o sudeste asiático, influenciado pela China. No contexto do século XXI, a importância da América Latina neste processo se faz presente, constatada a partir da crescente presença chinesa nas relações políticas, econômicas e comerciais com os países latino-americanos.
\end{abstract}

Palavras-Chave América Latina; China; reorientalização; sistema-mundo.

Abstract The present article seeks to delineate and debate the hypothesis of the Latin American importance for the Asian recentralization - or reorientalization - in the world-system. From the longue durée (the long term theory), it seeks to present the duality of a millenary world-system centered on Asia and the rise of an European world-system in the sixteenth century. Thus, the Asian peripherization before the apogee of the European capitalist world-system from the Industrial Revolution begins to be reversed in the late twentieth century, whose gravitational axis is rescentralized to Southeast Asia, influenced by China. In the context of the twentieth first century, the importance of Latin America in this process is present, evidenced by the growing Chinese presence in political, economic and commercial relations with Latin American countries.

Keywords Latin America; China; reorientalization; World-System.

a Doutorando em Economia Política Internacional pela Universidade Federal do Rio de Janeiro (UFRJ).

b Professor do curso de pós-graduação em Economia Política Internacional da UFRJ e coordenador do Laboratório de Estudos de Hegemonia e Contra-Hegemonia (LEHC/UFRJ) 


\section{INTRODUÇÃO}

O crescimento econômico da China tem provocado mudanças econômicas e geopolíticas no sistema-mundo. A partir do século XXI, constata-se a presença e influência da China nos países latino-americanos e, concomitantemente, uma maior participação dos países latino-americanos na pauta da agenda política e econômica chinesa. Seja através da análise do fluxo comercial, dos empréstimos e investimentos, das alianças estratégicas, há inúmeras evidências que ratificam a importância da América Latina para a recentralização asiática lastreada pela China.

O presente artigo busca delinear e debater a hipótese da importância latino-americana para a recentralização asiática - ou reorientalização - no sistema-mundo. A partir da perspectiva da longa duração, busca-se definir a dualidade de um sistema-mundo milenar centrado na Ásia e a ascensão de um sistema-mundo europeu. Assim, a periferização asiática diante do apogeu do sistema-mundo capitalista europeu a partir da Revolução Industrial começa a ser revertida no final do século XX, cujo eixo gravitacional é recentralizado para o sudeste asiático, influenciado pela China. No contexto do século XXI, a importância da América Latina neste processo se faz presente, constatada a partir da crescente presença chinesa nas relações políticas, econômicas e comerciais com os países latino-americanos.

O trabalho dividido-se em duas partes: na primeira, discute-se a visão do sistema-mundo milenar baseado no protagonismo asiático, a importância da América Latina para a formação do sistema-mundo europeu e algumas hipóteses para a perda da centralidade asiática no sistema-mundo. Na segunda parte, são apresentadas as constatações empíricas e metodológicas da nova ascensão asiática no século XXI, definindo-se a importância da América Latina no processo de reorientalização no sistema-mundo. Desse modo, partindo da premissa da ascensão/recentralização chinesa no sistema-mundo, busca-se ratificar o papel latino-americano neste processo, da mesma forma que são impostos novos dilemas estruturais para os países da região, com impactos sobre a agenda do desenvolvimento.

\section{1. ÁSIA E AMÉRICA LATINA: 0 SISTEMA-MUNDO NA LONGA DURAÇÃO}

\subsection{PROTAGONISMO ASIÁTICO NO SISTEMA-MUNDO MILENAR}

A visão de um sistema mundo milenar é, em parte, uma crítica a uma visão eurocêntrica da formação do sistema-mundo moderno, baseada nas obras de Wallerstein. No livro Before European Hegemony: The World System A.D. 125O1350, Janet Abu-Lughod descreve uma intensiva rede de trocas comerciais 
eurasiana, que constituiu um sistema-mundo que antecedeu o europeu em mais de cem anos, datado do século XIII. Assim, mais do que a preponderância europeia como o estopim do sistema mundial moderno, "the fall of the East" precedeu "the Rise of the West" (ABu-LUGHOD, 1989, p. 338), resultando numa mudança hegemônica do Oriente para o Ocidente no próprio estabelecimento do sistema-mundo europeu e, portanto, não se constituindo num novo, moderno sistema-mundo, e sim dando-se a continuação e evolução do sistema como um todo. Da mesma forma, discorrem Frank (1993; 1998) e Arrighi (2008).

No livro The World System: Five Hundred Years or Five Thousand?, Andre Gunder Frank e Barry K. Gills lançam a tese do one world-system, segundo a qual o sistema mundial contemporâneo possui pelo menos cinco mil anos (Frank; GILLS, 1993, p.3-4), com origem na arcaica economia Afro-Eurasiana. Ao combater o eurocentrismo ${ }^{12}$ a partir de uma história mundial humanocêntrica (FrANK; GILLS, 1993, p. 11) que busca deslegitimar os estudos históricos clássicos eurocêntricos referentes ao sistema-mundo, esses dois autores afirmam que os períodos antigos e medievais mantêm as mesmas características que Wallerstein apontou para a era pós-1500 de formação do sistema-mundo europeu: exploração e transferência de valor das periferias para o núcleo central do sistema, o imperativo da acumulação incessante de capital, alternância de períodos (cerca de 200 anos cada) de expansão e contração, e as rivalidades e sucessões hegemônicas (FrANk; GILls, 1993, p. 6-7; p. 301).

Our use of the term hegemon-rivalry refers to the political-economic predominance by a center of accumulation, wich alternates with periods of rivalry among several such centers of accumulation. Therefore, we argue that hegemon-rivalry has also characterized the world-system for thousands of years (Frank; GiLLS, 1993, p. 8).

Para os autores, todas as estruturas, processos e eventos históricos devem ser estudados como parte de um único processo, um único sistema-mundo. A partir de uma perspectiva histórico-mundial na qual todas as zonas da Eurásia antiga são analisadas com base na sua participação num processo econômico universal,

1 "We suggest that there is a common river and unity of history in a single world-system and that it is multicultural in origin and expression, which has been systematically distorted by Eurocentrism" (FRANK; GILls, 1993, p.17).

2 "For all of them, the rise of Europe was a unique 'miracle' and not a product of history and shifts within the world (system)" (FRANK; Gills, 1993, p.27). 
verifica-se que "Europe was ever 'marginal' and West Asia ever 'central"' (FRANK; GILls, 1993, p. 22). A própria conexão de Veneza e Gênova na Europa medieval com o Império Bizantino, as Cruzadas, as ligações entre a Europa e o mundo islâmico, o interesse nas Grandes Navegações ratificam a hipótese de que o centro do sistema se localizava no Oriente. "From a world-system perspective medieval Europe was socially, politically, and economically quite backward or less developed in comparison with the contemporary cores in the world-system, all of which lay to the East" (Frank; Gills, 1993, p. 24).

Em outros termos, a compreensão do sistema-mundo não é uma prioridade única e exclusiva da Europa; é uma metodologia aplicada "much further in space and time" (Frank; Gills, 1993, p. 30), cujas bases e características se assentam na acumulação cumulativa de capitais, nas trocas comerciais, na transferência de excedentes e na influência cultural, política, militar entre as suas partes.

What we seek to establish is that a process of accumulation existed in a world economic system long before the emergence of the "capitalist modern world-system" and that rhythms of expansion and contraction in this world-system/ economy have a continuity, which long predate (Frank; GiLLs, 1993, p.37).

Parte considerável da herança cultural e científica europeia possui influência da milenar sociedade chinesa. De todas as civilizações dos tempos pré-modernos, nenhuma possuía um nível tão avançado quanto a sociedade chinesa:

Huge libraries existed from early on. Printing by movable type had already appeared in eleventh-century China, and soon large numbers of books were in existence. Trade and industry, stimulated by the canal-building and population pressures, were equally sophisticated. Chinese cities were much larger than their equivalents in medieval Europe, and Chinese trade routes as extensive. Paper money had earlier expedited the flow of commerce and the growth of markets. By the later decades of the eleventh century there existed an enormous iron industry in north China, producing around 125,000 tons per annum, chiefly for military and governmental use-the army of over a million men was, for example, an enormous market for iron goods. It is worth remarking that this production figure was far larger than the British iron output in the early stages of the Industrial Revolution, seven centuries later! The Chinese were also probably the first to invent true gunpowder; and cannons were used by the Ming to overthrow their Mongol rulers in the late fourteenth century (KenNEDy, 1987, p. 6). 
A ênfase que se busca delinear é pautada na economia global centrada na preponderância da China e da Ásia no sistema-mundo milenar, que possui certas tendências e características gerais e se constitui numa dinâmica e estrutura de todo o sistema econômico mundial, ao longo do tempo e do espaço, e não somente uma parte desse todo, o sistema-mundo europeu. A centralidade chinesa se devia a sua maior produtividade absoluta e relativa na indústria, agricultura, transportes e comércio. “China's even greater, indeed the world economy's greatest, productivity, competitiveness, and centrality were reflected in its most favorable balance of trade" (FRANK, 1998, p. 127)

Em outros termos, autores como Frank (1998), Abu-Lughod (1989) e Arrighi (2008), com suas específicas análises e interpretações, buscam delinear que o "moderno sistema-mundo capitalista" não foi uma reinvenção, mas a continuação do mesmo sistema-mundo anterior, no qual o protagonismo e a centralidade do Leste Asiático na economia mundial durou até, pelo menos, meados de 1800, convivendo conjuntamente com a ascensão do sistema-mundo europeu.

So one of my early purposes in the present book is to show first that there already was an ongoing world economy before the Europeans had much to do and say in it. There are two naturally derivative points: One is to show that Asia, and especially China and India, but also Southeast Asia and West Asia, were more active and the first three also more important to this world economy than Europe was until about 1800 (Frank, 1998, p. xxiv).

As críticas de Frank (1998) ao eurocentrismo nas formulações do sistema-mundo se baseiam nestas prerrogativas, nas evidências de que a Europa não se expandiu e "incorporou" o resto do mundo em sua "economia-mundo/sistema europeu". Ao invés disso, a Europa tardiamente juntou, ou pelo menos cimentou os laços anteriormente mais frouxos, de uma já existente economia mundial do sistema. Portanto, a partir de uma perspectiva global, a Ásia, e não a Europa, foi o centro do sistema e protagonista na maior parte da história moderna.

\subsection{A AMÉRICA LATINA NA CONFIGURAÇÃO DO SISTEMA-MUNDO EUROPEU}

A formação do sistema-mundo europeu pode ser visualizada como a gênese histórica do capitalismo e o processo de criação das condições para a extração da mais-valia, consistindo num processo de acumulação de riquezas ocorrido na Europa entre os séculos XVI e XVIII que possibilitou as grandes transformações econômicas da Revolução Industrial. Um dos fatores para que essa concentração 
fosse possível foi a descoberta do Novo Mundo e de suas imensas riquezas no final do século XV. Assim, as descobertas dos territórios americanos foram basilares, uma vez que a extração de prata e ouro de seu território consistiu numa etapa importante para o processo de acumulação primitiva e posterior formação do sistema-mundo capitalista europeu.

A acumulação primitiva de capital é tratada por muitos pesquisadores como a gênese do modo de produção capitalista. Parte desse processo possui relação intrínseca com o sistema colonial nas Américas a partir do século XVI, que muito contribuiu com diversos fatores. Na visão de Maurice Dobb, o sentido da noção de acumulação primitiva anterior à produção capitalista deveria ser interpretado, em primeiro lugar,

como uma acumulação de valores de capital - de títulos a bens existentes e que se acumulam primordialmente para fins de especulação - e, em segundo, como acumulação em mãos de uma classe que, por virtude de sua posição especial na sociedade, é capaz de transformar esses títulos guardados em meios reais de produção (Dовв, 1976, p. 220).

O próprio autor aponta a influência na história da acumulação do aumento da quantidade de metais preciosos no século XVI. Em sua visão, para que no início se pudesse investir na indústria, dever-se-ia possuir como requisitos básicos reservas abundantes em mão-de-obra e acesso fácil a suprimentos de matérias-primas, juntamente com a produção de ferramentas e maquinaria. "Sem essas condições, o investimento industrial teria inevitavelmente sido frustrado e detido qualquer progresso maior, por mais esplêndidas que se tivessem tornado a riqueza e a posição da burguesia anteriormente" (Dовв, 1976, p. 226).

Nesse contexto, a América desempenha um papel vital para a formação desse tipo de capital e, consequentemente, para a formação do sistema-mundo europeu, onde

as descobertas de ouro e de prata na América, o extermínio, a escravização das populações indígenas, forçadas a trabalhar no interior das minas, (...) são os acontecimentos que marcam os albores da era da produção capitalista. Esses processos idílicos são fatores fundamentais da acumulação primitiva (MARX, 2008, p. 864). 
O sistema colonial, dessa maneira, fez com que prosperasse o comércio e a navegação, de modo que as sociedades que possuíam o monopólio eram poderosas alavancas de concentração de capital, cujas colônias ultramarinas "asseguravam mercado às manufaturas em expansão e, graças ao monopólio, uma acumulação acelerada. As riquezas apresadas fora da Europa pela pilhagem, escravização e massacre refluíam para a metrópole, onde se transformavam em capital" (MARX, 2008, p. 867). Assim, o papel preponderante que principalmente a América Latina desempenhou para a acumulação primitiva nesse período é essencial para se compreender a conflagração do sistema-mundo europeu e a gênese do modo de produção capitalista.

Desta forma, Macleod afirma que

uma das principais questões provocadas pelo influxo dos metais preciosos americanos é: qual foi seu papel na criação de um “sistema mundial” europeu? Muitos autores acreditaram que a prata americana, ela mesma um resultado da expansão europeia dos primeiros tempos, forneceu mais tarde a energia ou o lubrificante para a transmissão a uma grande parte do mundo de uma estrutura capitalista imposta pela Europa. (...) a carrera de Indias constituiu, num sentido mais geral, uma parte muito grande do complexo de fatores que resultaram no surgimento do capitalismo, na revolução industrial e na hegemonia da Europa no mundo inteiro (MACLEOD, 2012, p. 390).

Assim, tem-se uma relação dialética: a América desempenhou um papel relevante na gênese da economia capitalista mundial e na formação do sistema mundial europeu - principalmente com sua produção de metais preciosos nos séculos XVI e XVII, a qual se desenvolveu em estreita consonância com a dinâmica do capitalismo internacional - assim como auxiliou - indiretamente - no início da perda da centralidade do sistema mundo na região do Sudeste Asiático, cujo eixo gravitacional passou a ser a Europa e o Atlântico.

\subsection{A PERDA DO PROTAGONISMO ASIÁTICO}

As contendas no âmbito da teoria do sistema-mundo fomentam debates acerca da origem das diferentes formações econômicas, sociais e políticas no sistema-mundo, privilegiando o aspecto temporal e espacial da construção material em durações diferenciadas.

Seja através da análise de Wallerstein acerca da crise terminal do sistema-mundo tal qual estabelecido desde sua formação, de Arrighi com a crise do 
processo de acumulação específico e a constatação das quatro cidades-Estados que compõem os ciclos sistêmicos, ou de Gunder Frank com a redefinição da China como centro do mundo num único sistema-mundo, que nasce há cinco mil anos na Mesopotâmia, com a Rota da Seda, o fundamental numa análise histórica do sistema-mundo é a busca para além do jornalístico, do tempo presente, é a análise de aspectos do passado que possuem relação com as características do tempo presente.

Nesses termos, compreende-se que a história da Europa deve ser uma história dentre outras, um processo específico em que diversos sistemas convivem conjuntamente, sendo o sistema europeu apenas mais um elemento dessa dinâmica; assim, é essencial se modificar a visão da história, a partir de uma metodologia de esvaziamento da centralidade da concepção de mundo da Europa, tornando-a o que ela realmente é, uma visão de história regional.

Entretanto, é inegável que, simultaneamente à ascensão do sistema-mundo europeu, há uma perda do protagonismo milenar da Ásia no sistema mundo, cujo moderno sistema mundial é moldado - mas não formado - pelo mundo europeu, a partir da construção da economia anglo-americana.

Sucintamente, podem ser delineadas algumas hipóteses acerca da perda do protagonismo asiático, do porquê da perda de centralidade do Oriente e do alcance da hegemonia Ocidental no sistema mundo, sobretudo a partir de 1400 até 1750, período no qual a Ásia começa a perder força, abrindo espaço para a expansão europeia.

1) A Ásia limitou o mercado interno como prioritário, com prioridades demográficas e territoriais, uma vez que poderia gerar desemprego em massa;

2) o enorme aumento da população asiática, com tecnologias intensivas em mão-de-obra, que desencorajaria tecnologias poupadoras de mão-de-obra e inovações tecnológicas, assim como os problemas sócio-políticos referentes a essa grande população;

3) a proibição, por parte do império chinês, da construção de navios de grande porte, a partir de uma decisão político-estratégica de contenção das pressões territoriais mongóis no norte do país, cuja outrora avançada frota chinesa seria considerada custosa e dispensável, fazendo com que a China decidisse virar suas costas para o mundo (KeNNEDY, 1987, p.7);

4) as humilhações sofridas pelos chineses na Guerra do Ópio, como a abertura obrigatória de portos, privilégios ingleses no comércio com a China, indenizações de guerra e perda da posse da ilha de Hong Kong para os britânicos; 
5) substituição das redes comerciais asiáticas por redes americanas, afetando o Império Otomano e a Índia, uma vez que a América passa a ganhar cada vez mais protagonismo nos circuitos mercantis;

6) substituição de importações manufatureiras oriundas sobretudo da Inglaterra, berço da Revolução Industrial que modificou as relações econômico-comerciais no sistema-mundo;

7) a ampliação das redes de crédito na Europa, com maior circulação de fluxos monetários (oriundos, inclusive, da prata americana), cujas rendas coloniais baixaram o custo de produção europeu;

8) a maior capacidade europeia de se projetar no mundo através da capacidade ilimitada de expansão territorial e de capital.

Todos esses fatores foram elementos, instrumentos da inversão e transferência de protagonismo asiático para o eixo atlantista. Assim, concomitantemente a um momento específico de fraqueza dos asiáticos, houve o fortalecimento dos europeus (FrANk, 1998, p. 258), cuja "força militar real, mais do que a artilharia metafórica das mercadorias baratas, foi a chave para a subjugação do Oriente ao Ocidente” (ARrighi, 2008, p. 89).

A falta de envolvimento na expansão ultramarina, nos novos fluxos comerciais, na Revolução Industrial e na corrida armamentista à moda europeia tornou a China e todo o sistema asiático-oriental vulneráveis ao massacre militar, econômico e político das potências europeias em expansão. Quando houve o massacre, tornou-se inevitável a incorporação subordinada da Ásia oriental ao sistema europeu globalizante (ARrighi, 2008, p. 342).

\section{A RECENTRALIZAÇÃO ASIÁTICA NO SÉCULO XXI E A IMPORTÂNCIA DA AMÉRICA LATINA}

\section{1 "REORIENTALIZAÇÃO" DO SISTEMA MUNDO}

No início do século XXI um novo período no sistema-mundo se inicia. Novo século e nova fase sistêmica que tem na centralização asiática a sua característica mais importante.

Por mais de um século, desde a Primeira Revolução Industrial até as crises do petróleo na década de 1970, o Atlântico norte vem se configurando como o principal motor da economia global. Entre 1870 e 1972, a Europa e a América do Norte responderam por aproximadamente dois terços do crescimento do Produto Interno Bruto (PIB) mundial. Entretanto, no período de 2002 a 2012, esse valor foi 
reduzido para 36\%, enquanto a participação dos países do leste e sudeste asiático chegou a 44\% (WORLD BANK, 2013). Esses números evidenciam o deslocamento do centro de gravidade da produção mundial e prenunciam alterações na dinâmica de poder, na distribuição da renda e na lógica de conformação das cadeias globais de valor.

As transformações verificadas na estrutura industrial chinesa são decorrentes da articulação de políticas governamentais, a qual pode ser tomada como um dos fatores determinantes de sua estratégia contemporânea de desenvolvimento. $\mathrm{O}$ ciclo de expansão dos investimentos estatais da China ao longo dos anos 1990 foi acompanhado por uma estratégia industrial em que o governo selecionou 120 grupos empresariais para formar um national team em setores de importância estratégica (MEDEIROS, 2006). ${ }^{3}$

Atualmente, a China corresponde a um centro cíclico regional, fazendo da expansão do seu mercado interno um polo de expansão para a economia regional e global. Em outros termos, pauta sua estratégia de desenvolvimento na busca de uma inserção internacional, conhecida como going global. A partir dessa estratégia, foram elaboradas diretrizes para o investimento externo, que podem ser resumidas em três principais objetivos: acessar recursos naturais escassos no país, fomentar a industrialização e o desenvolvimento tecnológico das empresas nacionais, e aumentar a competitividade das empresas chinesas por meio da promoção de marcas no exterior e da construção de uma rede global de produção e fornecimento (Coelho; Masiero; Caseiro, 2015).

Essa nova inserção internacional chinesa suscitou diversos estudos e novas postulações teóricas. Em 2004, Joshua Cooper Ramo publicou um livro intitulado The Beijing Consensus, popularizando o termo "Consenso de Pequim". A fim de compreender o modelo de desenvolvimento que a China estaria implementando a partir de uma série de reformas econômicas ao longo dos anos com sucesso, esta estratégia estaria sujeita à emulação pelos outros Estados em desenvolvimento e, implicitamente, teria um forte elemento contra-hegemônico (VADELL, 2011).

De outro lado, alguns teóricos afirmam que as relações entre a China e os demais países em desenvolvimento apontam para uma complementaridade comercial dinamizada pela expansão comercial e financeira chinesa, pelo crescimento

3 Diversos centros de tecnologia foram desenvolvidos. Foram estabelecidas dezenas de zonas de desenvolvimento econômico e tecnológico (como as em Daliam, Tiajin, Fuzhou, Beijing, Shanghai) especialmente concebidas para formarem polos de crescimento voltados para a economia como um todo. Estas zonas passaram a receber massivos investimentos do governo em infraestrutura e muitas criaram parques industriais em alta tecnologia. 
mundial e pela elevação dos preços das commodities e dos recursos energéticos. Ou seja, essa nova relação Norte-Sul, assimétrica e complementar entre a China e algumas regiões em desenvolvimento, como é o caso dos países da América Latina, denomina-se como Consenso do Pacífico, ${ }^{4}$ que não pretende descrever o funcionamento ou as características de um modelo de desenvolvimento específico, mas um tipo de relacionamento Norte-Sul na sua fase comercial-financeira, cujo desenvolvimento é uma consequência direta das transformações globais, da ascensão chinesa e das próprias características do seu desenvolvimento (VADELL, 2011).

A ressurgência do gigante asiático pretende acelerar a integração da economia global, mas ao seu modo e a seu ritmo. Isso implica desenvolver e aumentar as relações comerciais e financeiras com outras regiões, realizando uma nova configuração na geografia da economia política internacional. Para Arrighi, este fato deve-se não à convergência para o caminho ocidental ${ }^{5}$ de uso intensivo de capital e de elevado consumo de energia, oriundo da Revolução Industrial, mas à fusão entre esse caminho e o caminho asiático, através da Revolução Industriosa, que faz uso intensivo de mão-de-obra e poupa energia, tendo uma capacidade distributiva que criou a possibilidade de difundir os benefícios do milagre da produção (via Revolução Industrial) para a vasta maioria da população mundial (ARRIGHI, 2008, p. 51-52).

4 Segundo Vadell (2011, p. 72-3), as características mais salientes desse novo Consenso do Pacífico seriam: “(i) o CP [Consenso do Pacífico] abre as margens de manobra política para países em desenvolvimento e subdesenvolvidos. O envolvimento da China na América Latina, mas também na África, no século XXI, apresenta-se como uma nova opção para os estados do 'Sul', em contraposição aos constrangimentos rígidos do CW [Consenso de Washington]. Seja mediante novas possibilidades de comércio, seja em investimentos na área de infraestrutura e nas indústrias extrativas ou com ajudas financeiras para quitar dívidas externas. (ii) A interdependência crescente entre a RPC [República Popular da China] e os países em desenvolvimento não se apresenta, no curto prazo, como uma ameaça para os EUA, e isso vale sobretudo para o hemisfério ocidental. Não obstante, os Estados Unidos têm se preocupado com a presença chinesa na região e têm pressionado para deixar clara essa relação. [...] (iii) Em terceiro lugar, a China tem como objetivo manter e promover a estabilidade nas mais diversas regiões para, dessa maneira, garantir a segurança nos investimentos e os contratos das relações comerciais (RATLIFF, 2009). (iv) Em quarto lugar, a RPC está surgindo como uma nova possibilidade de financiamento para os países com problemas financeiros da América do Sul. A diferença mais saliente em relação ao modelo de empréstimos das instituições financeiras internacionais como o FMI e o Banco Mundial é que a RPC não impõe condicionalidades políticas em troca de investimentos e ajuda. [..] (v) Finalmente, uma característica interessante do padrão de relacionamento do CP é a estratégia bilateral de negociação, seja nas assinaturas dos TLC [Tratados de Livre Comércio] com três países da região, seja na negociação com os países membros do Mercosul."

5 Para um grupo crescente de estudiosos, o ressurgimento econômico da China - seja qual for o resultado social final - deu origem a uma nova consciência de que há uma diferença histórica mundial fundamental entre os processos de formação do mercado e os processos de desenvolvimento capitalista. Faz parte dessa nova consciência a descoberta (ou redescoberta) de que, durante o século XVIII, o comércio e o mercado eram mais desenvolvidos na Ásia oriental em geral, e na China em particular, do que na Europa (ARrighi, 2008, p. 40). 
Ainda, a constatação do excepcional dinamismo do Leste Asiático deveria ser analisada como o produto de um único processo do sistema-mundo numa perspectiva de longa (500 anos), média (150 anos) e curta (50 anos) duração (ARRIGHI; HAMASHITA; SELDEN, 2003), que permitiria buscar conexões entre a ascensão atual e a ulterior posição na vanguarda do desenvolvimento mundial, anterior à ascensão do sistema-mundo europeu. Somente através da herança histórica da região se pode analisar a reorientalização no sistema mundo, no qual "the historical parameters of the East Asian region [...] have shaped and continue to shape both regional outcomes and the nature of interactions linking East Asia and the global political economy" (ARrighi; Hamashita; Selden, 2003, p.15).

Em suma, Arrighi resume de forma categórica a recentralização econômico-política do sistema mundial centralizado na Ásia oriental:

Todo o sistema de relações interestatais da Ásia oriental vêm se caracterizando por uma dinâmica de longo prazo que contrasta intensamente com a dinâmica ocidental [...]. Essa dinâmica diferente resultou na amplamente reconhecida primazia chinesa na formação do Estado e da economia nacional durante o século XVIII e no início do XIX. Mas também criou condições para a posterior incorporação subordinada do sistema da Ásia Oriental à estrutura do sistema europeu globalizante. Essa incorporação subordinada transformou, mas não destruiu, o sistema regional preexistente de relações internacionais. E, mais importante, contribui também para a transformação contínua do próprio sistema ocidental incorporador. O resultado foi uma formação político-econômica híbrida, que criou um ambiente especialmente favorável para o renascimento econômico da Ásia oriental (ARRIGHI, 2008, p. 321).

Pode-se constatar que a expansão da Ásia oriental também é reflexo da turbulência global, que preparou o palco para o seu desenrolar (ARRIGHI, 2008, p.159); ou seja, nos termos utilizados por Arrighi, a outrora hegemonia estadunidense no sistema internacional perdeu credibilidade, tornando-se uma pura dominação, uma "dominação sem hegemonia" decorrente da "crise terminal" dos Estados Unidos (ARRIGHI, 2008, p.161; p. 185).

As tentativas dos Estados Unidos de provocar o maior de todos os ajustes espaciais, transformando-se em Estado mundial, saíram pela culatra. Em vez de criar um Estado mundial, eles criaram um mercado mundial de volume e densidade sem precedentes, no qual a região dotada do maior suprimento de mão-de-obra 
barata e de alta qualidade leva vantagem competitiva decisiva. Não é por acaso histórico que essa região é a Ásia oriental (ARRIGHI, 2008, p. 370).

Concomitantemente, o gradualismo das reformas e do planejamento estatal chinês desde a Revolução Cultural, a reforma com "características chinesas", o projeto nacional de desenvolvimento baseado no "interesse nacional" chinês (seja pela via interpretativa do "socialismo de mercado" ou do "capitalismo de Estado"), as aberturas econômicas graduais e controladas, o "desenvolvimento não-capitalista baseado no mercado", a não subserviência aos preceitos do Consenso de Washington, a "ascensão" ou "coexistência pacífica", a dinamização político-econômica com seu entorno estratégico asiático, a política externa convergente com as etapas de desenvolvimento da política interna, dentre outros fatores, são possíveis causas para uma compreensão do ressurgimento do Oriente e, em particular, da China, no sistema mundial no século XXI.

\subsection{AS RELAÇÕES SINO-LATINOAMERICANAS NO SÉCULO XXI}

No sistema-mundo, uma economia que cresce a taxas de $10 \%$ ao ano ao longo de duas décadas influencia a economia mundial, alterando preços e deslocando fluxos de comércio e de investimento. Recentemente, verifica-se a constatação do interesse chinês na evolução de suas relações exteriores com a América Latina que, consequentemente, influencia tanto a região como um todo como o país asiático.

Em termos específicos de relações de política exterior para com a América Latina, o líder chinês Yang Shangkun expressou, em sua visita ao continente nos anos 1990, o que assinalou como "quatro princípios" latentes para tal aliança: que ambas as partes estabeleceriam relações cooperativas amigáveis com base nos Cinco Princípios de Coexistência Pacífica; ${ }^{6}$ que tanto o comércio bilateral quanto a cooperação econômica e tecnológica deveriam ser expandidos com visto ao interesse mútuo; que ambas as partes respeitassem os valores e tradições culturais de cada um; e, finalmente, que empreendessem esforços conjuntos visando lograr uma nova ordem política e econômica internacional, mais multipolar, consultiva e menos assimétrica (TsAi; Liu, 2012, p. 292-293). Desde meados da década de 1990 até a atualidade, diversos estadistas chineses reafirmaram a importância

6 Os Cinco Princípios constituem eixos norteadores fundamentais para a política externa chinesa. São eles: respeito mútuo pela soberania e integridade das outras nações; não-agressão mútua; não-interferência mútua nos assuntos internos de cada país; equidade e cooperação em prol do benefício mútuo; e, finalmente, coexistência pacífica (ZHANG, 2012, p. 59-61). 
da América Latina para a estratégia de política externa da China, cujos interesses econômicos e políticos passam a ser cada vez mais convergentes.

In 1988 Deng Xiaoping stated that 'China's policy is to develop and maintain good relations with Latin American countries, and make Sino-Latin American relations a model of South-South co-operation'. Former President Jiang Zemin commented during his trip to the region in 2001, that 'the 21st century will be a century of China and Latin America, co-operating in all areas hand in hand, and it will also be a century of the peoples in China and Latin America building a better tomorrow'. Current President Hu Jintao, addressing the Brazilian Congress in November 2004, stated that both Latin America and China have similar experiences in gaining national liberation, defending national independence and building up their countries. Therefore, both sides have the same feelings and a common language (RoETT, 2010, p. 208).

A potência asiática engajou-se no continente latino-americano de modo a expandir interações e fortalecer suas próprias reformas em curso, principalmente após sua adesão à Organização Mundial do Comércio (OMC), em 2001. Reforçando a crescente relevância da América Latina na estratégia global da China, o presidente Jiang Zemin fez uma visita de Estado a seis países em abril de 2001: Argentina, Brasil, Chile, Cuba, Uruguai e Venezuela. Em novembro de 2004, o presidente Hu Jintao realizou uma visita para Argentina, Brasil, Chile e Cuba a fim de consolidar ainda mais este novo relacionamento entre China e América Latina. Começando com uma reunião do fórum de Cooperação Econômica Ásia-Pacífico (APEC), em Santiago, Hu realizou uma série de visitas de Estado destinadas a demonstrar o seu conceito de "desenvolvimento pacífico da China”. Em 2008, o governo chinês lançou o documento intitulado China's Policy Paper On Latin America And The Caribbean, culminando no primeiro paper especificamente direcionado à América Latina.

After nearly 10 years of growing co-operation between China and LAC, the Chinese government's first policy paper on Latin America and the Caribbean demonstrates the serious consideration that Chinese policy-makers have begun devoting to establishing their strategy in the region (RoETT, 2010, p.202). 
O China's Policy Paper On Latin America And The Caribbean é considerado um marco nas relações sino-latinoamericanas, a partir do momento em que insere a América Latina nos interesses de política externa imediata, "namely that the People's Republic of China (PRC) now views its relations with the region from a 'strategic plane"” (RoETt, 2010, p. 221). Exemplo disso é que, ao longo dos últimos anos, houve a assinatura de inúmeros acordos intergovernamentais com mais de vinte nações latino-americanas e o estabelecimento de relações bilaterais mediante parcerias estratégias como a APEC (Asia Pacific Economic Cooperation). Além disso, "creció la cantidad de memorándums de entendimiento y acuerdos de cooperación en materia científica, intercambios culturales y otras áreas firmados entre Beijing y países latinoamericanos" (SLIPAK, 2014, p. 110).

No documento, cinco áreas são tidas como prioritárias para a China nas relações sino-latinoamericanas: comércio (a China é o segundo maior parceiro comercial da região, obtendo o primeiro lugar em alguns países), energia (prioridade de médio-longo prazo; interesse chinês em buscar diversificar suas fontes, principalmente a partir da dependência com o Oriente Médio), cooperação Sul-Sul (elemento-chave na política externa chinesa, na qual a América Latina possui papel importante), organizações regionais e multilaterais (tendo como principais exemplos os BRICS e suas instituições recém-criadas, a APEC e a convergência de decisões no âmbito da ONU) e laços culturais (busca da expansão de laços culturais, do turismo e das representações diplomáticas como objetivos governamentais) (RoETT, 2010, p. 203).

Nesse sentido, ao se considerar que a República Popular da China se projeta como potência econômica e política global no século XXI, deve-se analisar mais detidamente o tipo e padrão de relacionamento que essa potência está desenvolvendo com os países da América Latina e no novo quadro geopolítico/geoeconômico global. As relações entre a China e os países latino-americanos começaram a se intensificar efetivamente a partir de 2001 e 2002 (VADELL, 2007; RoETT, 2010; Moreno, 2015), em uma dinâmica que aproximou economicamente (do ponto de vista de comércio, investimento e crédito) os chineses com a região.

Entre 2002 e 2011, a corrente de comércio (exportações mais importações) entre a China e a região aumentou em aproximadamente 13 vezes. Neste período, as exportações da América Latina para a China elevaram-se de US $\$$ 6,2 bilhões

7 O documento é dividido em cinco partes principais: política, econômica, cultural e social, paz, segurança e judicial, e organizações regionais. 
para US \$ 86,3 bilhões, enquanto as importações foram multiplicadas por 127 (de US \$ , 4 bilhão para US $\$ 45,5$ bilhões) (Comtrade/ONU).

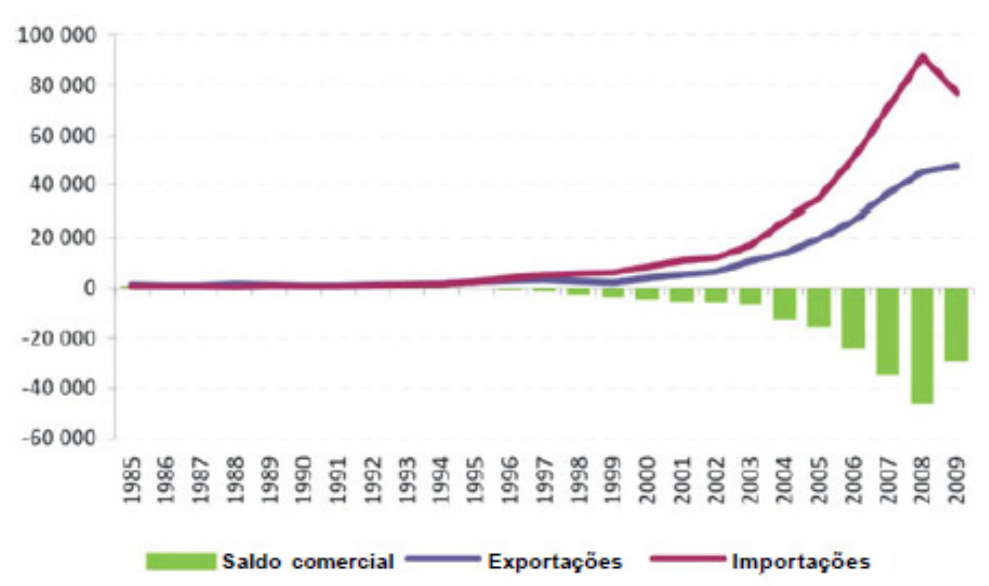

Gráfico 1. Exportações, importações e saldo comercial da América Latina e o Caribe com a China (em milhões de US\$) ${ }^{8}$. Fonte: VADELL (2011).

A China tem crescido recentemente como um importante destino de exportação para a América Latina, perdendo apenas para os Estados Unidos, passando a ocupar uma posição privilegiada nas relações comerciais com os países da região (ver anexo 1). Em 1993, a China consumiu menos de 2\% das exportações da América Latina, mas em 2013 foi responsável por 9\%. Entretanto, essa importância foi bastante desigual entre os diferentes setores de exportação. Como mostrado abaixo, a China triplicou a sua quota do total das exportações latino-americanas na última década, mais do que triplicou as exportações de produtos extrativos e duplicou a sua quota das exportações agrícolas. Mas a sua demanda por bens manufaturados continua constante, ficando em cerca de $2 \%$ das exportações de manufaturados da ALC (RAY ET AL, 2015).

8 Levando em consideração a explosão comercial da China com a América Latina, o intercâmbio entre os países da sub-região de México e América Central mostra um cenário e perspectivas diferentes em relação ao intercâmbio China-América do Sul, em dois sentidos. Em primeiro lugar, o comércio da China com a América do Sul apresenta-se muito mais equilibrado do que o comércio entre a China e México-América Central, que têm um déficit na balança comercial com a China muito preocupante. Em segundo lugar, a explosão das exportações latino-americanas, a partir de 2002, concentra-se em commodities e recursos energéticos e minerais. Em contrapartida, as importações vindas da China estão concentradas em produtos manufaturados. Por essa razão, os países da América do Sul, abundantes em recursos, foram e estão sendo os mais favorecidos com o aumento das exportações. 


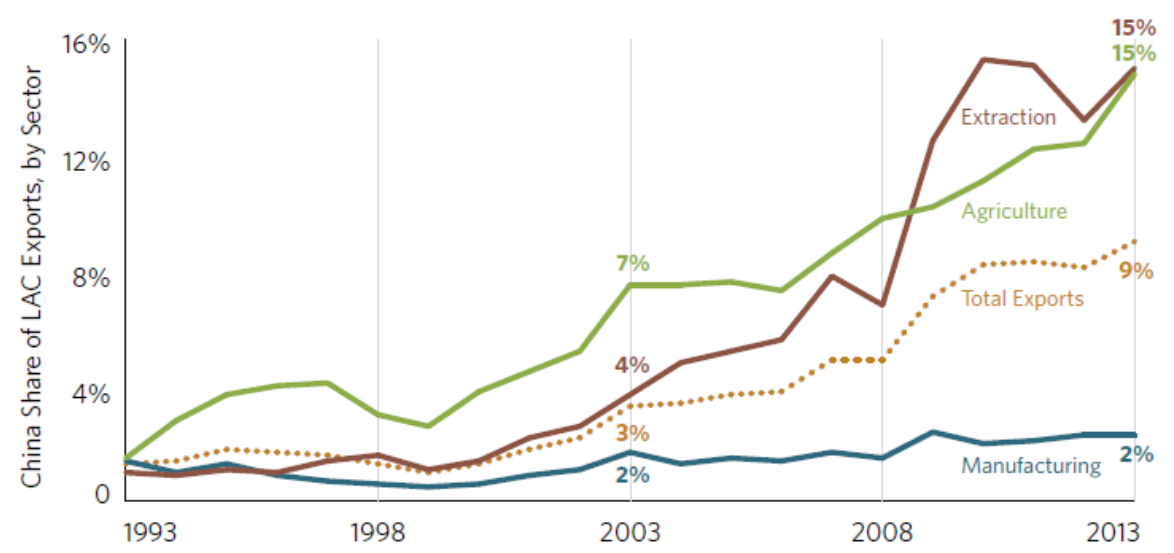

Gráfico 2. Participação da China nas exportações latino americanas por setor. Fonte: RAY et al. (2015).

A China tem sido um motor importante na expansão da exportação de bens agrícolas e extrativos da América Latina. Como mostra a figura abaixo, enquanto as exportações agrícolas e extrativas para a China cresceram como proporção do PIB, essas exportações para o resto do mundo permanecem estagnadas ou mesmo caíram durante a última década. A demanda chinesa também desempenhou um papel no aumento do nível geral da maioria das commodities durante o período, aumentando significativamente os termos de troca em favor da América Latina (RAY ET AL, 2015).

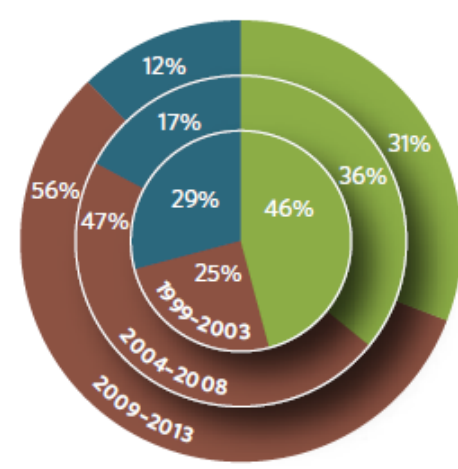

LAC Exports to China

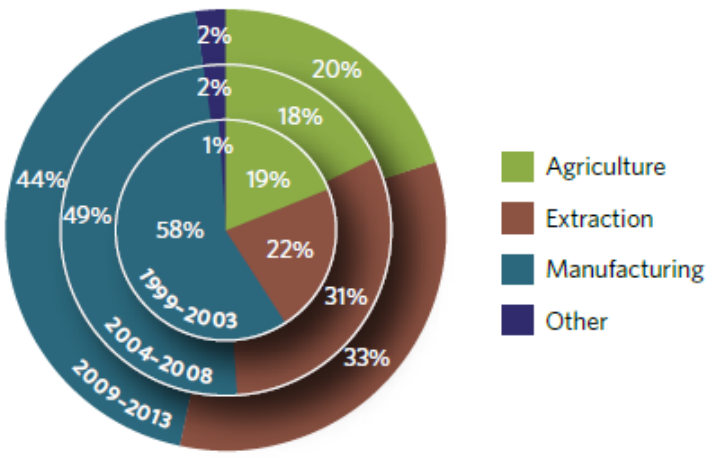

All LAC Exports

Gráfico 3. Composição da pauta exportadora da América Latina por setor. Fonte: RAY et al. (2015).

Entretanto, parte significativa dos países da região possui déficit comercial com a China. Ainda é preciso destacar que o padrão de comércio, mesmo nos países superavitários, foi marcado por uma relação assimétrica em que se verificaram elevados superávits em favor da região nos produtos primários e nas manufaturas 
intensivas em recursos naturais (ver anexo 2) e crescentes déficits nos produtos manufaturados (de baixa, média e alta intensidade tecnológica), sobretudo após a crise internacional, quando a China direcionou parte de suas exportações de manufatura da Europa e dos Estados Unidos para a região.

Em contrapartida, as exportações da China para a América Latina são compostas, fundamentalmente, por produtos eletrônicos e mecânicos. Concomitantemente, os países da América do Sul que possuem um parque industrial considerável são os mais prejudicados com o desenvolvimento dessa especialização comercial (VADELL, 2011).

Além da maior conexão no comércio, a China vem expandindo de forma expressiva o investimento direto especialmente na segunda metade da década de 2000, no qual "China has pledged to invest upwards of $\$ 250$ billion in Latin America over a decade" (RAY ET AL, 2015, p. 3). Esse novo papel desempenhado pela China fica circunscrito ao investimento greenfield, ao processo de aquisições e fusões realizadas por empresas da China na região e pela ampliação de empréstimos de bancos chineses (notadamente o China Development Bank) para firmas e governos.

$\mathrm{O}$ interesse primordial chinês tem sido voltado aos recursos naturais e energia (petróleo, cobre e ferro), para suprir sua demanda interna, mas também tem incluído, pós-crise internacional de 2008, investimentos em montagem de manufaturados, telecomunicações e têxtil. Entre 2005 e 2013, o fluxo de IED chinês para a América Latina cresceu de US $\$ 3,8$ bilhões para US $\$ 16$ bilhões, sendo que a partir de 2009 verificou-se um expressivo crescimento. $O$ valor acumulado para esse período foi de US\$101,8 bilhões, representado 12,7\% do total mundial dos investimentos da China.

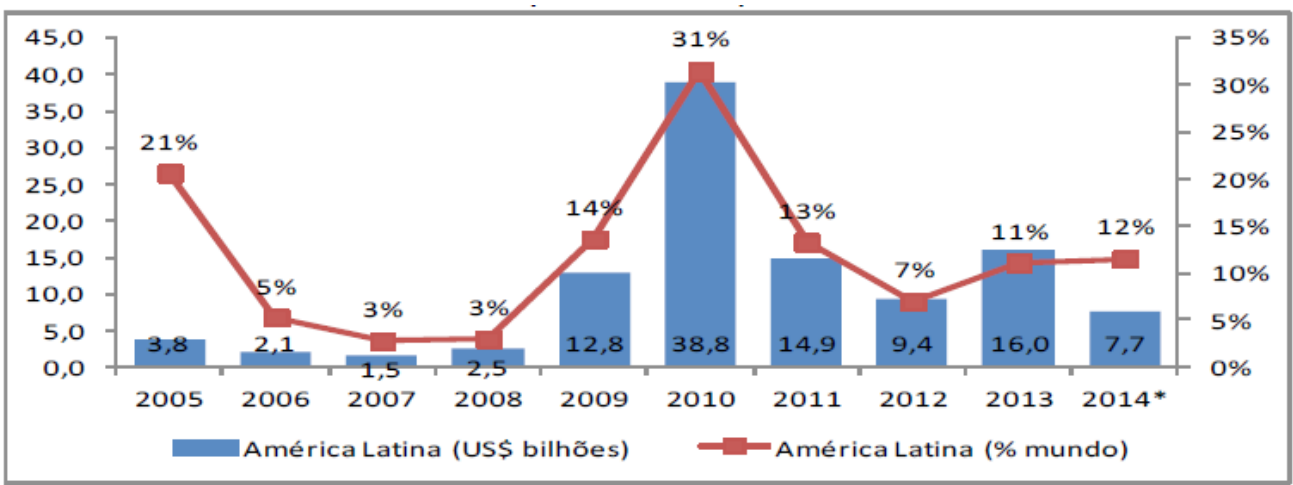

Gráfico 4. IED chinês na América Latina: 2005-2013 (US\$ bilhões; \%). Fonte: The China Global Investment Tracker/Heritage Foundation. 
O IED chinês na América Latina ficou concentrado, sobretudo, no setor de energia (54,6\% do total acumulado entre 2005 e 2013), sendo que deste valor $40 \%$ foram direcionados ao segmento do petróleo. As participações de outros setores de atuação das empresas chinesas na América Latina foram: 17,7\% em metais; 14\% no setor de transporte (automóveis); 4,6 \% na agricultura; 4,5\% em imóveis.

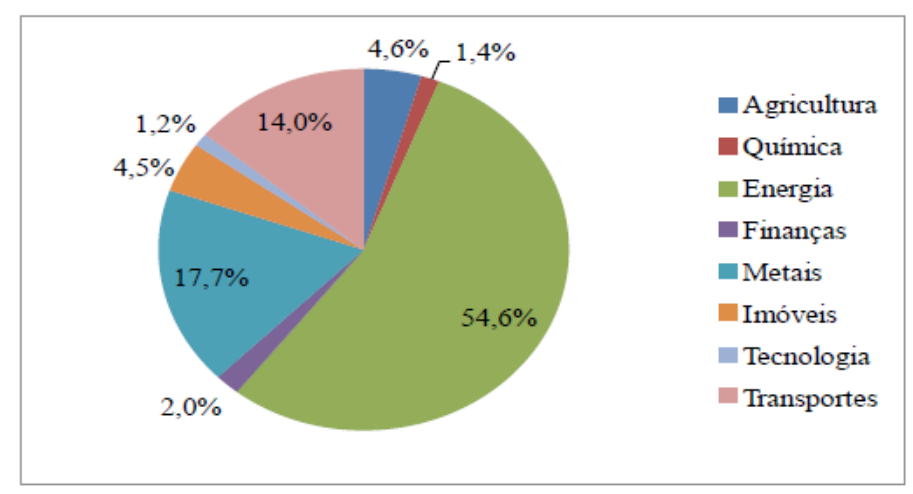

Gráfico 5. IDE chinês na América Latina: participação por setor econômico (acumulado 2005-2013 em \%). Fonte: The China Global Investment Tracker/Heritage Foundation.

Evidencia-se a estratégia chinesa de garantir o acesso às fontes de recursos naturais entre 2005 e 2013 (RAY ET AL, 2015). A América do Sul é o destino principal dos IED chineses, que podem ser divididos em três principais categorias, de acordo com seus propósitos: a) "orientados aos recursos naturais" (natural resource-seeking); b) "orientados ao mercado" (market-seeking) e c) "orientados à eficiência" (efficiency-seeking). A grande maioria dos IED com destino à América do Sul é orientada à exploração de recursos naturais, em setores de grande demanda da China, como cobre, aço, petróleo e soja (ver anexo 3). Ademais, pode-se observar investimentos em infraestrutura ligados ao objetivo de facilitar o escoamento desses produtos (VADELL, 2011).

Desde 2005, a China se tornou uma fonte adicional de financiamento para a região, notadamente para os países com dificuldades em acessar o mercado de crédito mundial. Com isso, superou a atuação do Banco Mundial e do Banco Interamericano de Desenvolvimento. Os bancos de desenvolvimento chineses adotam, por um lado, condicionantes financeiros e políticos menos rigorosos do que os bancos ocidentais e, por outro, realizam exigências vinculadas às suas estratégias nacionais (GALlagher; IRWIN; KolESKI, 2013).

Os empréstimos concedidos pelos bancos chineses (China Development Bank, Export-Import Bank of China, entre outros) às empresas e aos governos da América Latina totalizaram entre US\$ 118,5 e US\$ 125 bilhões no acumulado entre 2005 e 
2014 (Myers; Gallagher; Yuan, 2016). Desse total, US $\$ 19$ bilhões foram destinados ao governo e empresas da Argentina para investimento em energia e, sobretudo, em infraestrutura; US $\$ 22$ bilhões para as empresas brasileiras, sendo a maior parte para a exploração de petróleo no pré-sal brasileiro realizada pela Petrobras; US\$ 2,4 bilhões para o México para área de energia e infraestrutura; US\$ 2,3 bilhões para o Peru, voltados, sobretudo, para equipamentos de mineração; e US\$ 0,150 bilhão para empresas do Chile (ver anexo 4).

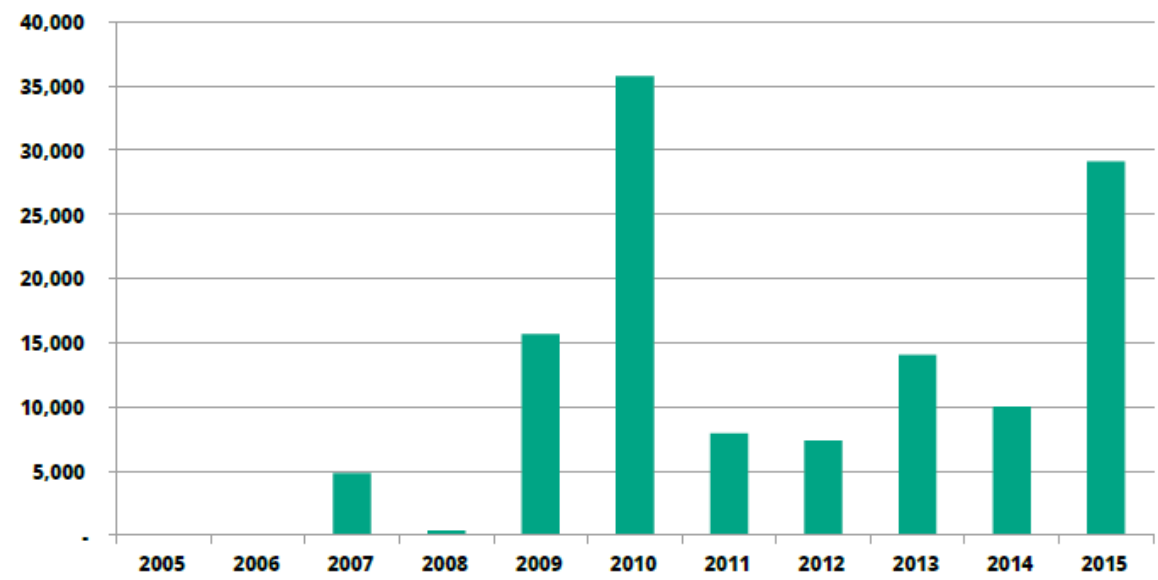

Gráfico 6. Finanças chinesas para a América Latina por ano, 2005-2015 (US\$ milhões). Fonte: Myers; Gallagher; Yuan, 2016.

Apesar de desaceleração do crescimento, as finanças chinesas para a América Latina expandiram-se consideravelmente em 2015. Como nos anos anteriores, os focos principais são as áreas de infraestrutura e matérias-primas. Recentemente, a China também estabeleceu aproximadamente US $\$ 35$ bilhões em fundos de infraestrutura para toda a região, além de outros projetos (Myers; GallaGHer; YUAN, 2016).

No contexto geral da América Latina, o fortalecimento e a interdependência das relações com a China, tanto ao nível individual dos países como regional, é atualmente um fator de reconfigurações econômicas e políticas estruturais (MoRENo, 2015, p. 25). Para a China, o interesse na região latino-americana é ratificado pela complementaridade econômica e pelos objetivos políticos, que ensejam um reordenamento geopolítico mundial cujas parcerias estratégicas são o mais elevado exemplo desta nova configuração, como é o caso dos BRICS. 


\subsection{BRASIL E CHINA NOS BRICS}

Partindo-se da premissa de que a China está modificando a balança de poder entre o centro e a periferia - e, inclusive, entre as relações na própria periferia ou Sul-Sul global -, gerando um conjunto de desdobramentos que podem provocar novas formas de cooperação e novas configurações geoeconômicas, os BRICS inserem-se nesse contexto de transição rumo à orientalização das relações internacionais; a ascensão dos países emergentes que não estão no centro de gravidade da antiga ordem econômica mundial implica no estabelecimento de um mundo multipolar, no qual o surgimento dos BRICS é um movimento de subversão estratégica da ordem estabelecida.

A criação do Novo Banco de Desenvolvimento dos BRICS e do Arranjo Contingente de Reservas fornece concretude à demanda por democratização da arquitetura financeira internacional e pela reforma das instituições de Bretton Woods. Com seu pontapé inicial na VI Cúpula dos BRICS, em 2014, os países atestaram a necessidade de mais investimentos globalmente - em especial nos países em desenvolvimento -, diante da insuficiência de recursos das instituições existentes. Investimentos estes utilizados principalmente para financiar infraestrutura, adaptação às mudanças climáticas e outras necessidades evidentes nos países mais pobres e/ou que tem dificuldades em obter recursos nas instituições tradicionais.

Nesse sentido, o Banco do BRICS é uma instituição em construção que se apresenta como um novo paradigma na análise do sistema econômico mundial para os próximos anos, como uma alternativa à dominação Ocidental dos países desenvolvidos a partir do Banco Mundial e do FMI, que demonstram a assimetria e o déficit democrático na governança global.

La intención del grupo para crear un banco demuestra un gran paso hacia una mayor institucionalización, tratando de mantener la cooperación, la expansión futura, y, sobre todo, la diversificación de las inversiones. En su conjunto, los BRICS buscan hacer sus deseos realidad hacia una orden internacional más inclusiva, democrática y multilateral (RodRIGUEs, 2015, p. 87).

Assim, o Banco se apresenta como a principal ferramenta de influência geopolítica dos BRICS na construção de um novo polo de liderança mundial. Para a China, a integração via BRICS é uma possibilidade real de se apresentar ao mundo como um modelo de superação das tradicionais relações assimétricas que perduram historicamente a partir das potências hegemônicas. "Otro enfoque 
usual es presentar a China como un nuevo posible hegemón con intenciones de desarrollar vínculos simétricos y cooperativos con nuestra región" (SLIPAK, 2014).

Como destaca Arrighi, duas características do chamado Consenso de Pequim se inserem nessa tentativa de ruptura com os consensos éticos, políticos e econômicos estabelecidos nas relações internacionais e que priorizam os países do Sul global:

A primeira é a "localização", o reconhecimento da importância de ajustar o desenvolvimento às necessidades locais, que diferem obrigatoriamente de um lugar para outro, em forte contraste com a receita de "tamanho único" do Consenso de Washington, cada vez mais desacreditado; e a segunda é o "multilateralismo", o reconhecimento da importância da cooperação entre os Estados para construir uma nova ordem global com base na interdependência econômica, mas que respeite as diferenças políticas e culturais, em forte contraste com o unilateralismo das políticas norte-americanas (ARRIGHI, 2008, p. 383).

\section{CONCLUSÃO}

O presente artigo buscou realizar um debate metodológico com a teoria do sistema-mundo partindo da hipótese da importância latino-americana para a recentralização asiática. Ainda, partiu-se da premissa de que a ascensão chinesa, ao reorganizar a divisão internacional do trabalho, impõe novos dilemas estruturais para os países latino-americanos, com impactos sobre a agenda do desenvolvimento de ambas as partes.

O desenvolvimento de relações amistosas com os países em desenvolvimento, incluindo a América Latina, é a postura básica da política externa e diplomática da China, que sublinha a importância da atuação do Estado, especificamente nos países em desenvolvimento, com o objetivo de criar novas vantagens comparativas capazes de atrair fluxos de investimentos para indústrias mais dinâmicas e intensivas em conhecimento. Assim, a recentralização asiática poderia tornar a acumulação estatal de capital predominante no sistema-mundo.

É importante mencionar que a recentralização do sudeste asiático, baseado nas altas taxas de crescimento da China, acarreta desdobramentos políticos e econômicos na América Latina, que geram simultaneamente uma dinâmica de conflito e cooperação, um horizonte de oportunidades e desafios:

1) a mudança da relação dos EUA com a região a partir da maior presença da China, realizando uma reconfiguração geopolítica hemisférica nunca antes enfrentada pelos Estados Unidos; 
2) a importância da China no impulso do crescimento econômico da região a partir de 2001-2002, fator fundamental para entender a recuperação econômica de muitos países da América do Sul após o fracasso das políticas econômicas neoliberais e, na contrapartida, intensificação do processo de desindustrialização e reprimarização das economias latino-americanas;

3) o mútuo apoio político entre a China e os países latino-americanos em foros e instituições multilaterais, ensejando a entrada da China na OMC em 2001, a criação do Foro China-Celac, de diversos acordos bilaterais com os países da região, e com a própria criação dos BRICS;

4) a China é altamente dependente de recursos naturais, o que faz com que tenha certa instabilidade no sistema internacional. Para os países latino-americanos, a solução seria realizar alianças com a China a fim de suprir o mercado chinês, sem assimetria tecnológica expressiva, realizando juntamente com os chineses um processo de industrialização dos recursos naturais regionais;

5) para a América Latina, o financiamento em infraestrutura realizado pela China, em portos, rodovias, estradas, ferrovias, são benéficos para a região reduzir os custos, diminuir gargalos e melhorar a competitividade. Entretanto, a dependência da exportação de commodities é um entrave pelo baixo valor agregado, vulnerabilidade de preços e variações internacionais de oferta e demanda. Os ganhos temporários dos termos de troca não devem substituir projetos de diversificação industrial de maior valor agregado e de fomento científico tecnológico, ou, do contrário, a inserção latino-americana na economia global será a mesma dos séculos XIX e XX;

6) diferentemente da constatação atual, segundo a qual o comércio China-América Latina reproduz a assimetria de uma relação Norte-Sul - em detrimento de laços Sul-Sul -, a China, no longo prazo, não deveria repetir a estratégia atlantista, e sim estabelecer relações comerciais com os demais países periféricos horizontalmente, de maneira a reduzir as fronteiras econômicas e tecnológicas dos países do Sul Global.

Nesta nova ordem mundial, é crucial para a América Latina compreender as características de seus vínculos com a China ao definir sua inserção global, uma vez que a região latino-americana serve aos objetivos geopolíticos da nova política externa chinesa de transformar o sistema internacional num sistema multipolar e, concomitantemente, na recentralização asiática no sistema-mundo. 


\section{REFERÊNCIAS BIBLIOGRÁFICAS}

Abu-Lughod, Janet. Before European Hegemony: The World System A.D. 1250-1350. New York, Oxford: Oxford University Press, 1989.

Arrighi, Giovanni. Adam Smith em Pequim: origens e fundamentos do século XXI. São Paulo: Boitempo, 2008.

Arrighi, Giovanni; Hamashita, Takeshi; Selden, Mark (Ed.). The Resurgence of East Asia: 500, 150 and 50 year perspectives. Londres, Nova York: Routledge, 2003.

Coelho, Diego Bonaldo; Masiero, Gilmar; Caseiro, Luiz. A ascensão da China e seus reflexos no Brasil: fundamentos e evidências para uma estratégia de desenvolvimento. Rev. Bras. Inov, Campinas, v. 14, p. 85-108, jul. 2015.

Dовв, Maurice. A Evolução do Capitalismo. $5^{\mathrm{a}}$ ed. Rio de Janeiro: Zahar, 1976.

FrAnk, Andre Gunder. ReOrient: Global Economy in the Asian Age. Berkeley, Los Angeles, Londres: University of California Press, 1998.

Frank, Andre Gunder; Gills, Barry K. The World System: Five Hundred Years or Five Thousand?. Londres, Nova York: Routledge, 1993.

Gallagher, Kevin P.; Myers, Margareth. China Latin-America Finance Database. Washington: Inter-American Dialogue, 2014.

Gallagher, Kevin P.; Irwin, Amos; Koleski, Katherine. ¿Un mejor trato? Análisis comparativo de los préstamos chinos en América Latina. Cuaderno de trabajo del CECHIMEX, $\mathrm{n}^{\circ}$. 1. México: Universidad Nacional Autónoma de México, Facultad de Economía, 2013.

KENNEDY, Paul. The rise and fall of the great powers: economic change and military conflict from 1500 to 2000. New York: Random House, 1987.

MACLEOD, Murdo J. “A Espanha e a América: o comércio Atlântico, 1492-1720”. In: BETHEL, Leslie (org.). História da América Latina: América Latina colonial, volume 1. 3 ed. , São Paulo: Editora da Universidade de São Paulo; Brasília, DF: Fundação Alexandre de Gusmão, 2012.

MARx, Karl. O capital: crítica da economia política. Livro I. Rio de Janeiro: Civilização Brasileira, 2008.

Medeiros, Carlos Aguiar de. A China como um Duplo Pólo na Economia Mundial e a Recentralização da Economia Asiática. Revista de Economia Política, São Paulo, v. 26, n. 3, p. 381-400, jul./set. 2006.

Moreno, Camila. O Brasil Made in China: para pensar as reconfigurações do capitalismo contemporâneo. São Paulo: Fundação Rosa Luxemburgo, 2015.

Myers, Margaret; Gallagher, Kevin; Yuan, Fei. Chinese Finance to LAC in 2015: Doubling Down. The Dialogue, 2016. 9 p. 
RAy, Rebecca et al. China in Latin-America: Lessons for South-South Cooperation and Sustainable Development. Boston: Boston University, 2015. 26 p.

RodRIGUES, Bernardo Salgado. "La nueva arquitectura financiera mundial: perspectivas del Banco de los Brics y del Banco del Sur.” In: Tavilla, Pablo; RobBa, Alejandro (Ed.). Congreso de Economía Política Internacional año 2014: los cambios en la economía mundial: consecuencias para las estrategias de desarrollo autónomo en la periferia. Moreno: Unm Editora, 2015, p. 79-92.

RoETT, Riordan. “China's deepening ties with Latin America: a work in progress”. In: BRESLIN, Shaun (Ed.). Handbook of China's International Relations. Londres: Routledge, 2010, p. 200-208.

SEVARES, Julio. ¿CooperaciónSur-Sur o dependencia a laviejausanza? Nueva Sociedad, Lima, p.11-22, jan./fev. 2007.

SLIPAK, Ariel M. América Latina y China: ¿cooperación Sur-Sur o "Consenso de Beijing”? Nueva Sociedad, Lima, v. 250, p. 102-113, mar./abr. 2014.

TsaI, Tung-Chieh; Liu, Tony Tai-Ting. "China’s Relations with Latin America”. In: Kavalsky, Emilian (ed.). The Ashgate Research Companion to Chinese Foreign Policy. Surrey: Ashgate, 2012.

VADELL, Javier. A China na América do Sul e as implicações geopolíticas do Consenso do Pacífico. Revista de Sociologia e Política, Curitiba, v. 19, p. 57-79, nov. 2011.

Zhang, Baijia. The Path of the CPC: Revolution, Construction and Reform. Beijing: Foreign Languages Press, 2012. 


\section{ANEXOS}

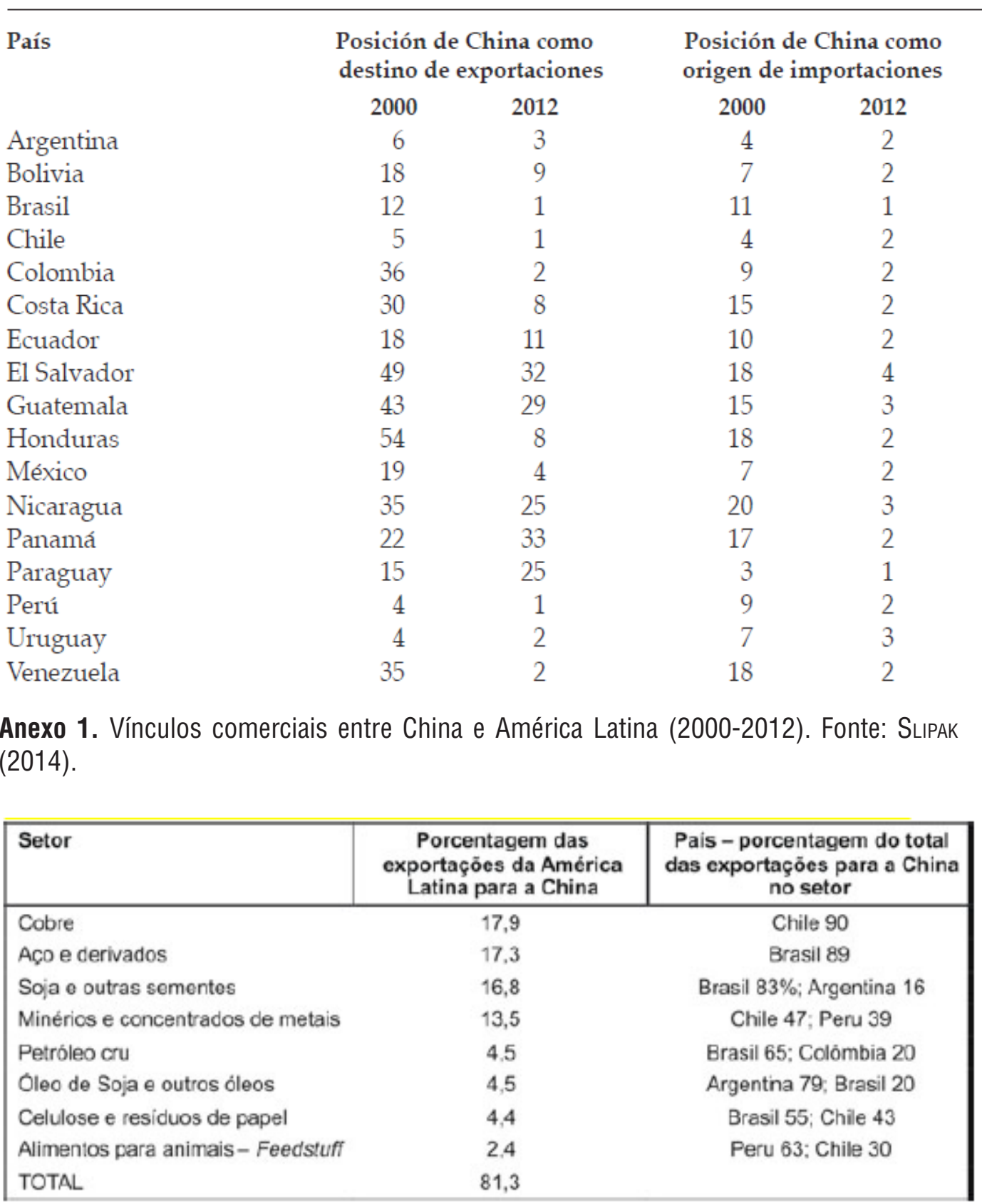

Anexo 2. Cinco países e oito setores que dominam o comércio entre América Latina e China. Fonte: VADELL (2011). 


\begin{tabular}{|c|c|c|c|c|c|c|c|c|}
\hline Ano & Mês & Investidor & $\begin{array}{l}\text { Cuant. } \\
\text { milhōes } \\
\text { (US\$) }\end{array}$ & $\%$ & Parceiro & Setor & Subsetor & Pais \\
\hline 2005 & Maio & Minnetals & 500 & & & Metais & & Cuba \\
\hline 2005 & Junho & Minnetals & 550 & 50 & Coldeco & Metais & Aço & Chile \\
\hline 2005 & Setembro & CNPC e Sinopec & 4420 & & Encana & Energia & Petróleo & Equador \\
\hline 2006 & Abril & Sinopec & 240 & & Petrobras & Energia & Gas & Brasil \\
\hline 2007 & Fevereiro & $\begin{array}{l}\text { Grupo Iiderado por Zijin } \\
\text { Mining }\end{array}$ & 190 & & Monterrico & Metais & Cobre & Peru \\
\hline 2007 & Junho & Chalco & 790 & & Peru Copper & Metais & Cobre & Peru \\
\hline 2007 & Dezembro & $\begin{array}{l}\text { Minmetals and Jiangxi } \\
\text { Copper }\end{array}$ & .450 & & $\begin{array}{l}\text { Northern Peru } \\
\text { Copper }\end{array}$ & Metais & Cobre & Peru \\
\hline 2008 & Maio & Chinalco & 2160 & & & Metais & Cobre & Peru \\
\hline 2009 & Janeiro & Huawei Technologies & 240 & & Costa Rica & Tecnologia & Telecon & Costa Rica \\
\hline 2009 & Fevereiro & Shougang Group & 1000 & & & Metais & Ferro & Peru \\
\hline 2009 & Julho & China Railways & 7500 & & & Transporte & Ferrovias & Venezuela \\
\hline 2009 & Setembro & $\begin{array}{l}\text { State Construction } \\
\text { Engineering }\end{array}$ & 100 & 2,75 & Baha Mar Resort & Turismo & & Bahamas \\
\hline 2009 & Novembro & Wuhan Iron and Steel & .400 & 22 & MMX Mneracao & Metais & Ferro & Brasil \\
\hline 2009 & Dezembro & $\begin{array}{l}\text { China Railway Construction } \\
\text { and Tongling Nonferrous }\end{array}$ & 650 & & $\begin{array}{l}\text { Corriente } \\
\text { Resources }\end{array}$ & Metais & Cobre & Chile \\
\hline 2009 & Dezembro & Hebei Zhongxin & .400 & & & Transporte & Autos & México \\
\hline 2010 & Fevereiro & Sany Heavy Industry & 200 & & & Imóveis & Construẹão & Brasil \\
\hline 2010 & Marco & $\begin{array}{l}\text { East China Mineral } \\
\text { Exploration and } \\
\text { Development Bureau } \\
\text { (Jiangsu) }\end{array}$ & 200 & & Itaminas & Metais & Ferro & Brasil \\
\hline 2010 & Marcó & CNOOC & 3100 & 50 & Bridas & Energia & & Argentina \\
\hline 2010 & Marco & Sinomach & 140 & & & Agricultura & & Venezuela \\
\hline 2010 & Marco & $\begin{array}{l}\text { China State Construction } \\
\text { Engineering }\end{array}$ & 2500 & & Baha Mar Resort & Imóveis & & Bahamas \\
\hline 2010 & Abril & CNPC & 900 & & & Energia & Petróleo & Venezuela \\
\hline 2010 & April & Chongqing Food Group & 320 & & & Agricultura & & Brasil \\
\hline 2010 & May & State Grid & 990 & & $\begin{array}{l}\text { Cobra, Elecnor } \\
\text { and Isolux }\end{array}$ & Energia & & Brasil \\
\hline 2010 & May & Sinochem & 3070 & 40 & Peregrino field & Energia & Petróleo & Brasil \\
\hline 2010 & June & Sinohydro & 2300 & & $\begin{array}{l}\text { Coca Codo } \\
\text { Sinclair }\end{array}$ & Energia & Hidro & Ecuador \\
\hline 2010 & August & Gezhouba & 670 & & Hidropaute & Energia & Hidro & Ecuador \\
\hline 2010 & August & Chery & 700 & & & Transporte & Autos & Brasil \\
\hline 2010 & October & Sinopec & 7100 & 40 & Repsol & Energia & Petróleo & Brasil \\
\hline 2010 & October & Minmetals & 2500 & & & Energia & Cobre & Peru \\
\hline 2010 & November & CNOOC & 2470 & 30 & Pan American & Energia & Petróleo & Argentina \\
\hline 2010 & November & CNPC and Sinopec & 610 & & & Energia & Petróleo & Ecuador \\
\hline 2010 & December & Sinopec & 2.450 & & Occidental & Energia & Petróleo & Argentina \\
\hline 2010 & December & $\mathrm{CIC}$ & 200 & & & Finanças & Investimentos & Brasil \\
\hline 2010 & December & CITIC & 400 & & & Real Estate & Construxăo & Venezuela \\
\hline 2010 & December & Three Gorges & 200 & & & Energia & Hidro & Ecuador \\
\hline TOTAL & & & 49310 & & & & & \\
\hline
\end{tabular}

Anexo 3. Investimento Direto Externo China-América Latina por setor. Fonte: VadelL(2011). 


\begin{tabular}{|c|c|c|c|c|c|}
\hline Data & Pais & Tipo & Credor & $\begin{array}{c}\text { Valor (USS } \\
\text { billhdes) }\end{array}$ & Properito \\
\hline 2005 & Brasl & Suderurgia & ICBC e BNPP & 0,201 & Equipamentos para sderurguia \\
\hline 2007 & Argentina & Outros & BDC & 0,030 & Setoe de Exportaçón \\
\hline 2007 & Brasl & Energia & BDC & 0,750 & Gasoduto \\
\hline 2008 & Pera & Mineraça & China EX-Im & 2000 & $\begin{array}{l}\text { Equipamentos para mineraçso } \\
\text { (Toromocho copper mine) }\end{array}$ \\
\hline 2009 & Pera & Infraestrulura & $B D C$ & 0,050 & Transporte/Infraestrutura \\
\hline 2009 & Brasal & Infraestrutura & BDC & 0.300 & $\begin{array}{c}\text { Ampliaçio da rede de } \\
\text { telecomunicaços (Telemar } \\
\text { Norte/On) }\end{array}$ \\
\hline 2009 & Brasal & Enerpha & BDC & 10000 & Plano de negdcios Presal \\
\hline 2009 & Mendco & Infraestrutura & BDC & 1,000 & $\begin{array}{l}\text { Equipamentos de ielecomunicaşos } \\
\text { (Amberka Movi) }\end{array}$ \\
\hline 2010 & Argentina & Infraestrutura & BDC & 10,000 & $\begin{array}{l}\text { Sistema ferrovisinio entre Buenos } \\
\text { Aimes, Rosirio e Crodobe (Coverno) }\end{array}$ \\
\hline 2010 & Argentina & Infraestrutura & $\mathrm{Cm}$ e BCC & 0,0085 & Sistema ferrovisirio \\
\hline 2010 & Argentina & Infraestrutura & CmeBDC & 0,273 & Trem de alta velocidade \\
\hline 2010 & Argentina & Outros & BDC & 00030 & Renovaça de emprestimo de 2000 \\
\hline 2010 & Brasal & Mineraçio & BDCEEX-IM & 1,200 & $\begin{array}{l}\text { Barcos para transporte de minerio de } \\
\text { ferro para a China (Vale comp) }\end{array}$ \\
\hline 2011 & Brasal & Energa & Stinopec & 0.390 & Plano de negacias Prosal \\
\hline 2011 & Pera & Outros & BDC & a.150 & Financiamento do Comercio \\
\hline 2011 & Mendico & Infraestrutura & BDC & 0,375 & Rede de telincomunicag bes (3G) \\
\hline 2011 & Chile & Infraestrutura & BDC & Q.150 & $\begin{array}{l}\text { Ampliaçio da rede de } \\
\text { tebcomanicacöes }\end{array}$ \\
\hline 2011 & Argentina & lnfraestrutura & Desconhecido & 1,400 & Linha de Metno de Buenos Aares \\
\hline 2012 & Brasal & Infraestruhura & BDC & 0,500 & Rede 3G \\
\hline 2012 & Pera & lnfraestruhura & BDC & 0,050 & Infraestrutura elytrica \\
\hline 2012 & Argentina & Energala & BDC & 0,200 & Projetos de energia nenoviwel \\
\hline 2013 & Mendico & Energha & China EX-IM & 1,000 & Equipamentos de perfuraça Offshom \\
\hline 2014 & Brasal & Mineraçio & China EX-IM & 5,000 & $\begin{array}{l}\text { Emprestimos pana a Vale para } \\
\text { compra de equipamentos e servicos }\end{array}$ \\
\hline 2014 & Brasal & Mineraçio & Banco da China & 2,500 & $\begin{array}{l}\text { Emprostimos para a Vale para } \\
\text { compra de servigos }\end{array}$ \\
\hline 2014 & Brasal & Energa & $\mathrm{CBC}$ & 1,100 & $\begin{array}{l}\text { Emprostimos para o Crupo Schahin } \\
\text { para aluguel de sondas de } \\
\text { perfuraciso }\end{array}$ \\
\hline 2014 & Argentina & Infraestrutura & China EX-IM & 0,162 & $\begin{array}{l}\text { Compra de } 150 \text { vagós para a linha } \\
\text { A do metro de Buenos Aines }\end{array}$ \\
\hline 2014 & Argentina & Infraestrutura & KCBce BDC & 2,100 & Lenha de trem de carpa de Belprado \\
\hline 2014 & Argentina & Energha Hadroeletrica & \begin{tabular}{|c|} 
KCBC, BDCe \\
Benco da China \\
\end{tabular} & 4,700 & Construcito de berragens \\
\hline $2005-14$ & \multicolumn{3}{|c|}{ Outros patess da America Latina } & 72.835 & \\
\hline $2005-14$ & \multicolumn{3}{|c|}{ Total da America Latina } & 118,531 & \\
\hline
\end{tabular}

Anexo 4. Empréstimos de bancos chineses a países da América Latina por setor. Fonte: Gallagher; Myers (2014). 